предметов. Обосновываются предложения по оснащению групп разминирования и совершенствование методов выполнения задач по очистке местности.

Ключевые слова: самодельное взрывное устройство, незаконные вооруженные формирования, взрывоопасный предмет, взрывчатые вещества, группа разминирования.

\title{
Organization of works on demining the area of explosive ordnance
}

R. Kolos, Y. Ftemov

Analysis of factors affecting the tasks of demining the area while conducting combat operations in eastern Ukraine, namely the uses of ammunition, lack of accounting documents established mine-explosive obstacles, changing the micro-relief terrain, long of ammunition for their clearance, destruction of buildings mines under the influence of the environment and continuous use of weapons in the areas of demining works.

Substantiated proposals for de-mining equipment group with the latest means of finding ammunition and ways to improve methods of cleaning tasks ground by hand and by mechanical systems. The attention to arrangements during demining traffic routes used to move units of various goods in which mainly used visual way to search for explosive devices for the tell-tale signs. In the places where there are hints of mining detectors are used to check the area. It is proposed to apply an additional group that after a certain period of time has re-check the road and give an opinion on the quality of the work.

The methods demining, manual (manual demining); mechanical (mechanical sweeping); explosive (mine-explosion); complex (complete clearance, which combines two or more ways). We present ways to improve the design of mine sweeps for explosive ordnance disposal that setting stretch marks at a height of $1.5 \mathrm{~m}$.

Author analyzed the advantages and disadvantages of the two methods of quality control of cleaning areas: the method of random sampling and identification of areas for mine clearance as an alternative basis - the area cleared of explosive objects or terrain is not free from explosive devices.

Keywords: improvised explosive device, illegal armed groups, explosive devices, explosives, mine clearance team.

УДК $534.01+355$

Х.І. Ліщинська ${ }^{1}$, Л.Ф. Дзюба ${ }^{2}$

${ }^{1}$ Наџіональна академія сухопутних військ імені гетьмана Петра Сагайдачного, Львів

2 Львівський державний університет безпеки життєдіяльності, Львів

\section{МОДЕЛЮВАННЯ ДИНАМІКИ ЕЛЕМЕНТІВ СИСТЕМ ЗАХИСТУ ВІД ФАКТОРІВ УРАЖЕННЯ}

Ударне навантаження великої інтенсивності на елементи конструкиій негативно впливає на міцність та призводить до їх раптового руйнування. Для оцінки дії ударного навантаження на стержневий елемент конструкиї використаний інтеграл Дюамеля. Ударне навантаження змодельоване ударним імпульсом напівсинусоїдальної форми короткої тривалості та з великою амплітудою. Реакиія стержня на удар розрахована у вигляді прогину в місиі прикладання ударного навантаження. Досліджено вплив способу закріплення кінців стержня, його довжини та розмірів поперечного перерізу на величину реакиії на удар.

Ключові слова: стержень, прогин, власна частота, ударний імпульс.

\section{Постановка проблеми}

Оцінити дію факторів ураження на елементи захисних конструкцій та військової техніки можна натурними випробуваннями на полігонах, які матеріально затратні та вимагають наявності готової конструкції; випробуваннями на спеціальних лабораторних стендах, які не завжди відтворюють діючі в реальних умовах ударні імпульси, та теоретичними дослідженнями ще на етапі проектування 3 використанням розрахункових моделей елементів конструкцій. А безпечність їх експлуатації залежить від достовірності даних про ударну міцність, стійкість конструкції тощо. Інтенсивне ударне навантаження, окрім негативних коливних процесів, може призвести до раптового руйнування як окремого елемента конструкції, так і конструкції загалом. Вказані питання і є розглядом даної роботи. 


\section{Аналіз останніх досліджень і публікацій}

Для ударного навантаження характерним $\mathrm{e}$ короткий час дії та збудження коливних процесів як під час удару, так і після його закінчення. Ударною дією вважають згідно 3 [1, 2] таке неперіодичне кінематичне чи силове збудження механічної системи, час дії якого порівняний $з$ найменшими періодами власних коливань системи і яке викликає значне відносне переміщення елементів конструкції. Значні переміщення внаслідок інтенсивної ударної дії супроводжуються значними динамічними i контактними напруженнями, що негативно впливає на міцність. Отже, для оцінки динамічних властивостей елементів конструкцій доцільно прогнозувати їхню поведінку при ударі. У роботі [3] досліджено поведінку елементів конструкції, які можна моделювати круглими неметалевими пластинами, на дію ударного імпульсу з великою амплітудою.

Однак сучасні конструкції машин та споруд містять багато елементів, розрахунковими моделями яких можна вважати стержні. У роботі [4] проаналізовано поведінку стержневої конструкції на дію ударного навантаження. Однак конструкції подані або у вигляді ферм, або змодельовані стержнем лише 3 консольним закріпленням. Інші способи закріплення не розглянуті.

\section{Формулювання мети статті}

Метою роботи $\epsilon$ визначення реакції стержневого елемента конструкції за різних способів закріплення його кінців на дію ударного імпульсу малої тривалості та великої інтенсивності і дослідження впливу геометричних параметрів стержня на величину реакції на удар.

\section{Виклад основного матеріалу}

У разі ударної дії диференціальне рівняння руху стержня на підставі теорії поперечного удару С.П. Тимошенко має вигляд [5]

$$
E I \frac{\partial^{4} w}{\partial x^{4}}+\rho A \frac{\partial^{2} w}{\partial t^{2}}=P(t) \delta\left(x-x_{1}\right),
$$

де $w(x, t)$ - поперечне переміщення точок стержня 3 координатою $x ; E$ - модуль Юнга матеріалу стержня; $I$ - осьовий момент інерції поперечного перерізу стержня; $\rho$ - густина матеріалу; $A$ - площа поперечного перерізу стержня; $P(t)$ - сила ударної дії; $\delta$ - дельта-функція (одиничний миттєвий імпульс); $x_{1}$ - координата точки удару на стержні, уздовж якого спрямована вісь $x$.

Для розв'язування диференціального рівняння (1) приймаємо нульові початкові умови

$$
w(x, 0)=0 ; \quad \frac{\partial w(x, t)}{\partial t}=0 .
$$

Крайові умови для стержня залежать від способу закріплення його кінців.

Переміщення точок стержня внаслідок удару можна подати у вигляді

$$
w(x, t)=\sum_{i=1}^{n} f_{n}(t) \cdot X_{n}(x),
$$

де $X_{n}(x)$ - балочні функції, які $є$ власними формами згинальних коливань стержнів [5]. Функцію $f_{n}(\mathrm{t})$ визначають з рівняння [5]

$$
\ddot{f}_{n}(t)+\omega_{n}^{2} f_{n}(t)=\frac{X_{n}\left(x_{1}\right)}{\rho A \int_{0}^{l} X_{n}{ }^{2}(x) d x} \cdot P(t),
$$

де $n$ - номер форми та частоти коливань; $\omega_{n}-$ відповідна власна частота згинальних коливань.

Розв'язок диференціального рівняння (4) за нульових початкових умов (2) подають у вигляді інтегралу Дюамеля [5]

$$
f_{n}(t)=\frac{X_{n}\left(x_{1}\right)}{\omega_{n} \rho A \int_{0}^{l} X_{n}{ }^{2}(x) d x^{0}} \int^{t} P(t) \sin \omega_{n}(t-\tau) d \tau .
$$

Після підстановки (5) в (3) отримаємо вираз для прогину стержня в місці удару 3 координатою $x=x_{1}$ як реакцію на дію ударного імпульсу

$$
y=w\left(x_{1}, t\right)=\sum_{n}^{\infty} \frac{X_{n}^{2}\left(x_{1}\right)}{\omega_{n} \rho A \int_{0}^{l} X_{n}^{2}(x) d x^{0}} \int_{0}^{t} P(t) \sin \omega_{n}(t-\tau) d \tau(6)
$$

У разі шарнірного обпирання кінців стержня (рис. 1), коли на обох кінцях стержня завдовжки $l$ справедливі такі крайові умови:

$$
w(0)=0, E I \frac{\partial^{2} w(0)}{\partial x^{2}}=0, w(l)=0, E I \frac{\partial^{2} w(l)}{\partial x^{2}}=0,
$$

балочна функція має вигляд [5]

$$
X_{n}(x)=\sin \beta_{n} x,
$$

де $\beta_{n}=\sqrt[4]{\frac{\rho A \omega_{n}^{2}}{E I}}-$ корені частотного рівняння;

$\rho$ - густина матеріалу.

3 урахуванням цього, вираз для прогину шарнірно обпертого стержня у місці удару запишемо так

$$
w\left(x_{1}, t\right)=\sum_{n}^{\infty} \frac{\sin ^{2} \beta_{n} x_{1}}{\omega_{n} \rho A \int_{0}^{l} \sin ^{2} \beta_{n} x d x^{0}} P(t) \sin \omega_{n}(t-\tau) d \tau .
$$

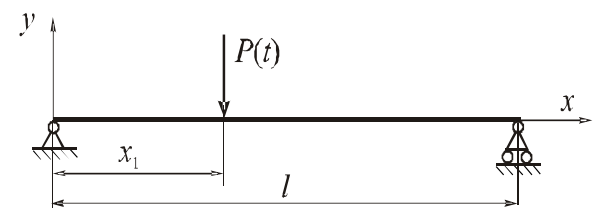

Рис. 1. Схема шарнірного закріплення кінців стержня 
У разі жорсткого закріплення кінців стержня (рис. 2), коли на обох кінцях стержня завдовжки $l$ справедливі такі крайові умови:

$$
w(0)=0, \frac{\partial w(0)}{\partial x}=0, w(l)=0, \frac{\partial w(l)}{\partial x}=0,
$$

балочна функція має вигляд [5]

$$
\begin{gathered}
X_{n}\left(\beta_{n} x\right)=-4\left(S_{3}\left(\beta_{n} x\right) \cdot S_{4}\left(\beta_{n} l\right)+\right. \\
\left.+S_{3}\left(\beta_{n} l\right) \cdot S_{4}\left(\beta_{n} x\right)\right),
\end{gathered}
$$

де $S_{3}(\beta x)=\frac{1}{2}(\operatorname{ch} \beta x-\cos \beta x)$,
$S_{4}(\beta x)=\frac{1}{2}(\operatorname{sh} \beta x-\sin \beta x)-$ функції Крилова.

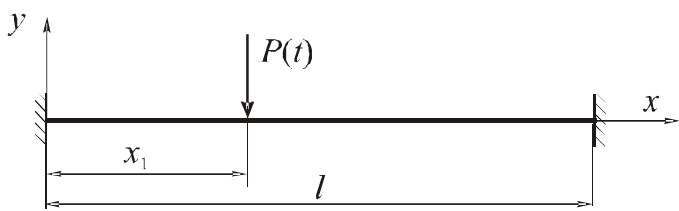

Рис. 2. Схема жорсткого закріплення кінців стержня

3 урахуванням (8) в (6) прогин жорстко закріпленого стержня у місці удару опишемо залежністю:

$$
w\left(x_{1}, t\right)=\sum_{n}^{\infty} \frac{\left(-4\left(S_{3}\left(\beta_{n} x_{1}\right) \cdot S_{4}\left(\beta_{n} l\right)+S_{3}\left(\beta_{n} l\right) \cdot S_{4}\left(\beta_{n} x_{1}\right)\right)\right)^{2}}{\omega_{n} \rho A \int_{0}^{l}\left(-4\left(S_{3}\left(\beta_{n} x\right) \cdot S_{4}\left(\beta_{n} l\right)+S_{3}\left(\beta_{n} l\right) \cdot S_{4}\left(\beta_{n} x\right)\right)\right)^{2} d x} \times \int_{0}^{t} P(t) \sin \omega_{n}(t-\tau) d \tau
$$

Для консольного стержня, коли один кінець жорстко закріплений, а другий вільний (рис. 3), справедливі такі крайові умови

$$
w(0)=0, \frac{\partial w(0)}{\partial x}=0,
$$

а балочна функція має вигляд [5]

$$
\begin{gathered}
X_{n}\left(\beta_{n} x\right)=4\left(S_{2}\left(\beta_{n} l\right) \cdot S_{3}\left(\beta_{n} x\right)-\right. \\
\left.-S_{1}\left(\beta_{n} l\right) \cdot S_{4}\left(\beta_{n} x\right)\right),
\end{gathered}
$$

де $S_{1}(\beta x)=\frac{1}{2}(\operatorname{ch} \beta x+\cos \beta x)$,

$$
w\left(x_{1}, t\right)=\sum_{n}^{\infty} \frac{\left(4\left(S_{2}\left(\beta_{n} l\right) \cdot S_{3}\left(\beta_{n} x_{1}\right)-S_{1}\left(\beta_{n} l\right) \cdot S_{4}\left(\beta_{n} x_{1}\right)\right)\right)^{2}}{\omega_{n} \rho A \int_{0}^{l}\left(4\left(S_{2}\left(\beta_{n} l\right) \cdot S_{3}\left(\beta_{n} x\right)-S_{1}\left(\beta_{n} l\right) \cdot S_{4}\left(\beta_{n} x\right)\right)\right)^{2} d x} \times \int_{0}^{t} P(t) \sin \omega_{n}(t-\tau) d \tau .
$$

$S_{2}(\beta x)=\frac{1}{2}(\operatorname{sh} \beta x+\sin \beta x)-$ функції Крилова

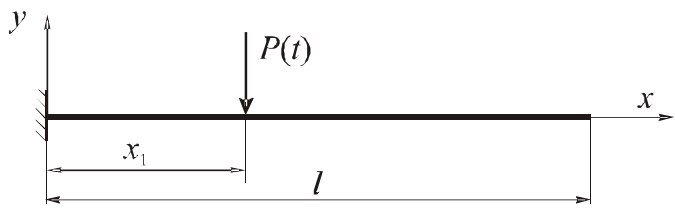

Рис. 3. Схема закріплення консольного стержня

3 урахуванням (10) в (6) отримаємо вираз для прогину консольного стержня у місці удару
Інтегруванням виразів (7), (9), (11) визначаємо прогини стержня за відповідного способу закріплення його кінців у разі дії короткочасного ударного імпульсу. Для дослідження обрали сталевий стержень $\left(E=2 \cdot 10^{11}\right.$ Па, $\left.\rho=7850 \frac{\text { кг }}{\mathrm{M}^{3}}\right)$ завдовжки $l$ з прямокутним поперечним перерізом висотою $h$ та шириною $b$. Підсумовування у виразах (7), (9), (11) під час інтегрування виконували за першими двома формами власних коливань $(n=1,2)$, оскільки встановили, що вищі форми власних коливань істотно не впливають на величини прогинів. Корені частотних рівнянь для різних способів закріплення згідно з [5] приймали такими: для шарнірно обпертого стержня - $\beta_{1}=3,142 ; \beta_{2}=6,283$; для защемленого стержня $-\beta_{1}=4,730 ; \beta_{2}=7,859$ для консольного стержня $-\beta_{1}=1,875 ; \beta_{2}=4,694$.

Табличя 1

Частоти власних коливань сталевих стержнів

\begin{tabular}{|c|c|c|c|}
\hline \multicolumn{2}{|c|}{ Власна частота коливань } & $\omega_{1}$, рад/с & $\omega_{2}$, рад/с \\
\hline \multirow{2}{*}{$\begin{array}{c}\text { Шарнірне } \\
\text { обпирання } \\
\text { кінців стержня }\end{array}$} & $h=2$ мм & 28,79 & 115,11 \\
\cline { 2 - 4 } & $h=4$ мм & 57,49 & 229,89 \\
\cline { 2 - 4 } & $h=8$ мм & 115,08 & 460,16 \\
\hline \multirow{2}{*}{$\begin{array}{c}\text { Жорстке } \\
\text { кінріплення } \\
\text { кінц стержня }\end{array}$} & $h=2$ мм & 65,24 & 180,11 \\
\cline { 2 - 4 } & $h=4$ мм & 130,96 & 359,70 \\
\hline \multirow{2}{*}{$\begin{array}{c}\text { Консольне } \\
\text { закріплення } \\
\text { стержня }\end{array}$} & $h=2$ мм & 260,79 & 719,96 \\
\cline { 2 - 4 } & $h=4$ мм & 20,47 & 128,32 \\
\cline { 2 - 4 } & $h=8$ мм & 40,98 & 256,84 \\
\hline
\end{tabular}

Прогини стержня відповідно до (7), (9), (11) залежать від власних частот коливань $\omega_{n}$. Значення першої та другої власних частот для сталевих стержнів прямокутного поперечного перерізу 
завширшки $b=40$ мм та заввишки $h$ обчислені для різних крайових умов та вказані в табл. 1 .

Зовнішня ударна дія на стержень моделювалась напівсинусоїдальним ударним імпульсом (рис. 4) 3 тривалістю дії 2 мс та прискоренням 3 амплітудою 1 тис. $g(g=9,81 \mathrm{M} / \mathrm{c})$.

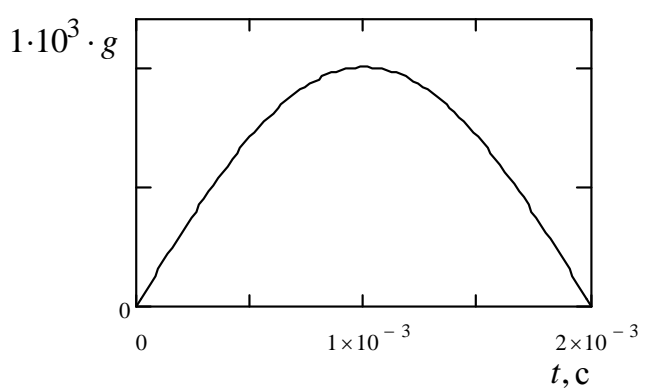

Рис. 4. Форма ударного імпульсу

На рис. 5 показані реакції прямокутних сталевих стержнів різних довжин на ударну зовнішню дію у разі прикладання навантаження посередині стержня $\left(x_{1}=l / 2\right)$ за різних способів закріплення їх кінців. Розміри поперечного перерізу стержнів: $h=4$ мм, $b=40$ мм. На рис. $5 a$ зображено прогини шарнірно обпертого стержня, на рис. 5 б - прогини консольного стержня, на рис. 5 в жорстко закріпленого стержня. Криві 1 на рис. 5 відповідають прогинам стержня завдовжки 0,5 м, криві $2-0,75$ м, криві $3-1$ м.

3 наведених графіків видно, що значення прогинів у місці удару є найменшими у разі жорстко закріплених обох кінців стержня. Для стержня завдовжки 0,5 м прогин дорівнює $3,978 \cdot 10^{-6}$ м (рис. 5 в, крива 1), що набагато менше від прогину консольного стержня такої ж довжини, що становить $6,709 \cdot 10^{-3}$ м (рис. 5 б, крива 1). Однак досягти в реальній конструкції через піддатливість опор абсолютно жорсткого закріплення практично неможливо. Якщо ж приймають у розрахунковій моделі таке закріплення, то слід враховувати піддатливість опор як у розрахунках власних частот, так і в крайових умовах.

3 порівняння прогинів стержнів різної довжини, кінці яких закріплені шарнірно, консольно чи жорстко (рис. 5), видно, що найменші прогини у місці удару виникають у найдовших стержнях. Збільшення довжини стержня вдвічі (від 0,5 м до 1 м) зменшує прогин від удару в 2 рази у разі шарнірного обпирання кінців, майже в 6,28 раза для стержня консольного з одним вільним кінцем та у 5,62 раза у разі жорсткого закріплення обох кінців. При цьому найменшими все одно залишаються прогини для випадку жорсткого закріплення.

Отже, найбільше реагує на дію ударного імпульсу консольний стержень довжиною 0,5 м, прогин якого посередині сягає практично 7 мм (рис. 5 б). Тому такий спосіб закріплення елемента конструкції, що працює при великих ударних навантаженнях, є явно недоцільним. Вільний кінець стержня потрібно обов'язково певним чином закріпити, можливо, пружним обпиранням, щоб зменшити прогини, які виникають як реакція на дію ударного імпульсу.
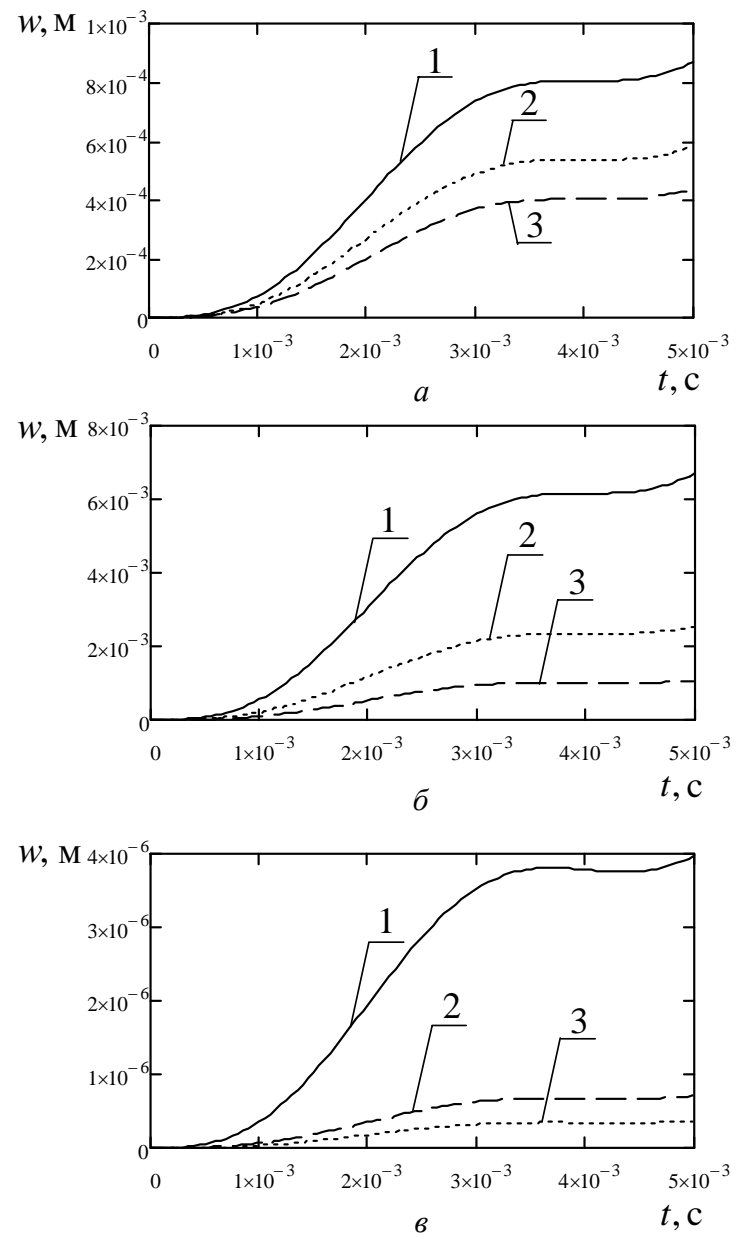

Рис. 5. Реакції стержнів на дію ударного імпульсу

Оскільки для моделювання ударних та вібраційних процесів у стержневих елементах конструкцій за розрахункову схему найчастіше приймають стержень 3 шарнірно обпертими кінцями, розглянемо, як впливають розміри поперечного перерізу на реакцію такого стержня від дії удару. На рис. 6 показані реакції на дію ударного імпульсу стержня завдовжки 0,5 м 3 шарнірно обпертими кінцями. Крива 1 на рис. 6 показує реакцію за найменшої висоти перерізу $h=2$ мм, крива $2-h=4$ мм, крива $3-h=8$ мм. Зі збільшенням висоти перерізу в 4 рази прогин зменшується від 1,763 мм до 0,417 мм, тобто в 4,23 раза. Отже, збільшення жорсткості поперечного перерізу на згин зменшує відгук стержневої конструкції на дію ударного імпульсу. 


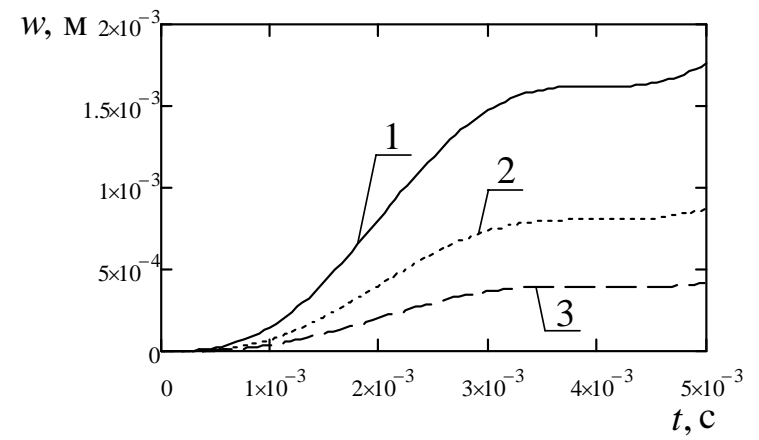

Рис. 6. Реакції шарнірно обпертого стержня на удар за різної висоти прямокутного поперечного перерізу при ширині $b=40 \mathrm{mм}$

Для стержня завдовжки 0,5 м 3 розмірами поперечного перерізу $h=4$ мм та $b=40$ мм, кінці якого закріплені шарнірно, визначені прогини у разі дії ударного імпульсу в різних точках по довжині стержня. Якщо ударне навантаження прикладене в точці 3 координатою $x_{1}=0,00001 \cdot l$, що практично збігається з місцем закріплення кінця стержня, то прогин становить $1,423 \cdot 10^{-11}$ м, посередині стержня, коли $x_{1}=0,5 \cdot l$ - прогин $8,719 \cdot 10^{-4}$ м, у точці 3 координатою $x_{1}=0,9999 \cdot l \quad$ прогин дорівнює $1,321 \cdot 10^{-8}$ м. Отже, біля опор від дії ударного навантаження стержень практично не деформується.

\section{Висновки}

Моделюючи за допомогою інтеграла Дюамеля реакцію сталевого стержня на дію ударного імпульсу, встановлено, що найменші прогини в місці удару виникають у стержні 3 жорстко закріпленими кінцями. Однак конструктивно досягти такого способу закріплення майже неможливо, оскільки опори стержня завжди матимуть певну податливість. Отже, якщо за розрахункову схему приймати такий спосіб закріплення, то слід враховувати піддатливість опор у визначенні власних частот та для моделювання реакції.

Консольний стержень недоцільно розміщувати в конструкціях, на які діють ударні навантаження, оскільки в місці удару виникають значні переміщення, що негативно відобразиться на характеристиках міцності. У разі необхідності такого конструктивного вирішення переміщення вільного кінця стержня потрібно обмежити додатковим обпиранням.

Якщо за розрахункову схему елемента конструкції приймати стержень 3 шарнірним обпиранням кінців, що $є$ певною ідеалізацією реальних умов закріплення, то реакцію стержня на дію ударного імпульсу можна зменшити, вибираючи відповідні геометричні розміри стержня та розміри його поперечного перерізу.

\section{Список літератури}

1. Круглов Ю.А. Ударовиброзащчита машин, оборудования и аппаратуры / Ю.А. Круглов, Ю.А. Туманов // Л.: Машиностроение, 1986. - 222 c.

2. Пеллинеи В.С. Измерение ударных ускорений / В.С. Пеллинеи // М.: Изд-ство стандартов, 1975. - 287 с.

3. Дзюба Л.Ф. Моделювання реакиій механічної системи на дію ударного імпульсу / Л.Ф. Дзюба // Науковий вісник: 3б. наук. техн. пр. Тези міжнародної конференції «Лісотехнічна освіта і наука на рубежі ХХІ століття». Львів: УкрдЛТУ, 1995. - С. 35-38.

4. Цуканова Е.С. Анализ применимости динамических конечных элементов в задачах теории колебаний и удара стержневых конструкиий: дис. канд. техн. наук 05.23.17 / Е.С. Цуканова; Брянский гос. техн. yн-m. - Б., 2016. -83 c.

5. Вибрачии в технике: Справочник в 6 m. T. $1 /$ Под ред. В.В. Болотина. - М.: Машиностроение, 1978. $352 c$.

Рецензент: д.т.н., проф. В.Р. Пасіка, Національний університет «Львівська політехніка», Львів.

\title{
Моделирование динамики элементов систем защиты от факторов поражения
}

\author{
Х.И. Лищинская, Л.Ф. Дзюба
}

Ударная нагрузка большой интенсивности на элементы конструкций отрицательно влияет на прочность и вызывает внезапное их разрушение. Для оиенки действия ударной нагрузки на стержсневой элемент конструкиии использован интеграл Дюамеля. Ударная нагрузка смоделирована ударным импульсом полусинусоидальной формы малой длительности и с большой амплитудой. Реакция стержня на удар рассчитана в виде прогиба в месте приложения ударной нагрузки. Исследовано влияние способа закрепления концов стержня, его длины и размеров поперечного сечения на величину реакиии на удар.

Ключевые слова: стержень, прогиб, собственная частота, ударный импульс. 


\section{Simulation of dynamic of devices of systems of protection from defeat factors}

Kh. Lishchynska, L. Dzuba

Scientific article perspective. To estimat action of factors of defeat on the elements of protective constructions and military technique is possible: by model tests on polygons; by tests on the special laboratory stands and theoretical researches yet on the stage of planning with the use of calculation models of elements of constructions. The safety of elements of constructions exploitation depends on authenticity of information about its shock strength and stability.

The intensive shock loading can reduce in destruction both a separate constructive part, and a construction as a whole. For the shock loading characteristic is: a short time of action in comparison with the least periods of eigentones of construction and and evocation of the considerable relative moving of elements of construction. Significant transitions are accompanied big dynamic and contact tensions, that negatively influences on durability. Consequently, for the estimation of dynamic properties of elements of constructions it is expedient to forecast their conduct at a blow.

The purpose. The purpose of work is determination of reaction of the cored element of construction at the different methods of fixing of its ends on the action of shock impulse of small duration and large intensity. Also research of influence of geometrical parameters of bar is on the size of reaction on a blow.

Essence of researches, used methods. The reaction of the cored element of construction on a blow is certain from the decision of differential equation of motion of bar on the basis of theory of transversal blow of S. P. Timoshenko. Initial conditions are accepted zero. Boundary conditions depended on the method of fixing of ends of bar. Moving of points of bar in the place of blow is calculated after the integral of Duhamel taking into account the first two forms of bend eigentones. A shock impulse is given with a semisinewave form.

The obtained results and conclusions. As a result of work the certain moving of points of bars is in the place of blow at three methods of fixing of ends: joint doing all the washing, hard jamming and cantilever fastening. Influence of geometrical parameters of steel bar is analysed on the size of reaction on a blow. It is indicated on pointlessness of placing of cantilever bar in constructions which work at the action of the shock loading.

Keywords: core, deflection, eigentones, shock impulse. 